\title{
A EFICÁCIA HORIZONTAL DOS DIREITOS FUNDAMENTAIS E A LIMITAÇÃO DA AUTONOMIA PRIVADA COMO MECANISMO DE PROTEÇÃO DO CONSUMIDOR SUPERENDIVIDADO.
}

\author{
HORIZONTAL EFFECTIVENESS OF FUNDAMENTAL RIGHTS AND \\ LIMITATIONS OF PRIVATE AUTONOMY AS PROTECTION MECHANISM TO \\ OVERINDEBTEDNESS CONSUMER.
}

${ }^{1}$ Michele Silveira Mendonça

\section{RESUMO}

O objetivo do presente trabalho é analisar a eficácia horizontal dos direitos fundamentais e a limitação da autonomia privada como forma de proteção do consumidor superendividado. Para tanto, se faz necessária a apreciação das principais teorias do instituto da aplicação horizontal. Neste sentido, é realizada uma revisão bibliográfica de algumas das principais obras sobre o tema. Após tal análise, é verificada possibilidade de ponderação com o princípio da autonomia privada e sua limitação como forma de garantir a proteção à dignidade do consumidor superendividado, como forma de tornar a relação jurídica desigual entre ele e o fornecedor mais justa.

Palavras-chave: Eficácia horizontal dos direitos fundamentais, Autonomia privada, Superendividamento

\begin{abstract}
The objective of this study is to analyze the horizontal effectiveness of fundamental rights and the limitation of private autonomy as a means to protect overindebted consumers. For that, it is necessary to examine the main theories concerning the horizontal application institute. Thus, it is performed a literature review of some of the major works on the subject. After that, it is verified the possibility of weighting with the private autonomy principle and its limitations in order to ensure the protection of the dignity of overindebted consumers and to make fairer the unequal legal relationship between him and the supplier.
\end{abstract}

Keywords: Horizontal effectiveness of fundamental rights, Private autonomy, Overindebtedness

\footnotetext{
${ }^{1}$ Mestranda em Direito pela Universidade Estácio de Sá - UNESA, São Paulo (Brasil). Servidor Público pelo Tribunal de Justiça do Estado do Rio de Janeiro - TJ, Rio de Janeiro (Brasil). E-mail: michelemadv@gmail.com
} 


\section{Introdução}

O acesso fácil e irrestrito ao crédito em uma sociedade de massificação de consumo, entre outros fatores, acaba fomentando o superendividamento. Não há, no ordenamento jurídico nacional, uma lei específica que regule a situação do superendividado e de suas obrigações, constituídas dentro do campo de sua autonomia privada. Deste modo, faz-se necessária a aplicação dos direitos fundamentais às relações privadas como modo de proteção da dignidade destas pessoas.

A horizontalização dos direitos fundamentais é objeto de estudos e controvérsias na doutrina nacional e estrangeira. De fato, a irradiação dos direitos fundamentais para os demais ramos do direito, o que inclui o direito privado, é meio de garantir a dignidade da pessoa humana, valor fundante do sistema jurídico brasileiro. No entanto, a aplicação dos direitos fundamentais acaba por colidir com outros princípios, como a autonomia privada.

Assim, o objetivo do presente trabalho é analisar a eficácia horizontal dos direitos fundamentais e a limitação da autonomia privada como forma de proteção do consumidor superendividado. Para tanto, a revisão bibliográfica sobre o tema é o método de pesquisa utilizado e, através dela, será verificado se, diante da desigualdade fática entre as partes e a violação dos direitos fundamentais, há possibilidade equilibrar a relação jurídica e torná-la mais justa.

\section{Superendividamento: um problema real}

O superendividamento pode ser definido como uma situação momentânea, porém não instantânea, em que o um indivíduo tem seus ativos desvalorizados ou mesmo já comprometidos por seus passivos. Ou seja, uma situação em que uma pessoa física tem toda ou grande parcela de suas receitas já comprometidas e alocadas para pagamentos de compromissos retroativos.

Para Marques, o superendividamento pode ser entendido como: "impossibilidade global de o devedor pessoa física, consumidor, leigo e de boa-fé, pagar todas as suas dívidas atuais e futuras de consumo (excluídas as dívidas com o Fisco, oriundas de delitos e de alimentos)"”. Ou seja, é uma impossibilidade manifesta pelo devedor de boa-fé de fazer face ao conjunto de suas dívidas, exigíveis e não pagas. 
Tal conceito é preciso em apresentar os requisitos exigidos pela doutrina, dos quais se destacam a necessidade de ser consumidor e estar de boa-fé. $O$ fato gerador do superendividamento pode ter razões diversas como: perda de emprego, doenças, separações entre casais, aplicações malsucedidas ou mesmo, simplesmente, descontrole das contas do tomador, prejudicando o adimplemento de despesas rotineiras.

O pensamento da massificação do consumo e de concessão de crédito foi capaz de fomentar a economia do país, gerando mais riqueza e fazendo circular um número de dividendos ainda maiores. Com esse modelo utilizado em ampla escala e de forma irrestrita iniciou-se, no final do século XX e início do XXI, ciclos de crise, com consequências sociais, como altas taxas de juros, aumento do desemprego, estagnação econômica, crise na produção industrial, saturação do setor terciário da economia, além do superendividamento dos consumidores. Esse modelo econômico é encontrado em diversos países, não sendo o problema do superendividamento uma exclusividade nacional.

A doutrina ${ }^{2}$ classifica o superendividamento em ativo e passivo. Entende-se por superendividamento ativo a situação de endividamento crítico, gerada por falta de experiência ou mesmo capacidade da pessoa física em questão em fazer a gestão de suas contas, caracterizando-se por um consumo descontrolado. O superendividamento ativo é fomentado em parte pelo marketing agressivo das instituições bancárias e financeiras fornecedoras de crédito, assim como das empresas fornecedoras de bens e serviços.

Já o superendividamento passivo não se dá por questões ligadas à vontade da pessoa natural, mas sim a acontecimentos e casos fortuitos. Caso em que o consumidor não esperava que determinada situação acontecesse e por isso seu planejamento financeiro não é capaz de atender a essa nova demanda. Apenas como forma de ilustração, é possível citar: desemprego, problemas de saúde, mortes, acidentes, nascimento de filhos, entre diversos outros.

Em ambos os casos, há a impossibilidade de adimplemento pelo consumidor, caracterizando o superendividamento. Este é um problema que perdura na sociedade brasileira independentemente do atual cenário de crise econômica, que, certamente o agravará. Através da pesquisa sobre o endividamento e inadimplência do consumidor realizada mensalmente pela 
Confederação Nacional do Comércio desde o ano de 2010, é possível vislumbrar a dimensão do superendividamento no Brasil.

O quadro abaixo ${ }^{3}$, extraído da referida pesquisa, bem representa a situação de endividamento das famílias brasileiras em junho de 2015. Destas, 7,9\% - percentual que representa um universo de 1.145.655 famílias - admitem que não conseguirão quitar seus débitos:

\begin{tabular}{|c|c|c|c|}
\hline & \multicolumn{3}{|c|}{ Síntese dos Resultados } \\
& $\begin{array}{c}\text { Total de } \\
\text { Endividados }\end{array}$ & $\begin{array}{c}\text { Dívidas ou Contas em } \\
\text { Atraso }\end{array}$ & $\begin{array}{c}\text { Não Terão Condições de } \\
\text { Pagar }\end{array}$ \\
\hline Jun/14 & $62,5 \%$ & $19,8 \%$ & $6,6 \%$ \\
\hline Mai/15 & $62,4 \%$ & $21,1 \%$ & $7,4 \%$ \\
\hline Jun/15 & $62,0 \%$ & $21,3 \%$ & $7,9 \%$ \\
\hline
\end{tabular}

Este índice de endividamento se mantém relativamente constante ${ }^{4}$ desde que a pesquisa foi iniciada, o que demonstra a gravidade do problema. Ademais, a pesquisa informa que 41,8\% dos endividados possuem débito em atraso em tempo superior a 90 dias e que $22,9 \%$ dos endividados comprometeram mais de $50 \%$ de sua renda apenas para o pagamento de dívidas.

No entanto, os débitos foram contraídos pelos consumidores dentro do campo de autonomia privada. Em que pese a tramitação do Projeto de Lei $n^{\circ} 283$ de $2012^{5}$, que dispõe sobre a prevenção e tratamento do consumidor superendividado, não há no Brasil uma lei específica sobre o tema. Assim, questiona-se se a proteção de tais consumidores poderá ser feita através da aplicação horizontal dos direitos fundamentais e se isso importaria na violação da autonomia privada das partes envolvidas nas relações creditícias. Deste modo, se faz mister a análise das principais teorias sobre a aplicação dos direitos fundamentais às relações privadas.

\section{Eficácia horizontal dos direitos fundamentais}

Com a consolidação da ideia de constituição como norma fundamental e a retomada do prestígio dos Direitos humanos no pós-guerra, não se mostrou mais viável a lógica liberal de

\footnotetext{
${ }^{3}$ CNC - Confederação Nacional do Comércio. Pesquisa Nacional de Endividamento e Inadimplência do Consumidor (Peic). [on line]. Disponível na internet via WWW. URL: < http://www.cnc.org.br/sites/default/files/arquivos/graficos_peic_-_junho_2015.pdf>. Última atualização em 07 de julho de 2015. p. 2. ${ }^{4}$ CNC - Confederação Nacional do Comércio. Pesquisa Nacional de Endividamento e Inadimplência do Consumidor (Peic). 2015 [on line]. Disponível na internet via WWW. URL:<http://www.cnc.org.br/central-do- conhecimento/pesquisas/economia/pesquisa-nacional-deendividamento-e-inadimplencia-do-c-7>. Última atualização em 07 de julho de $2015 .{ }^{5}$ Este projeto encontra-se atualmente em trâmite no Senado.
} 
separação absoluta entre direito privado e direito público, que vigeu no mundo ocidental durante o século XIX. Em decorrência disto, houve, e de certa forma ainda há, uma resistência na aplicação dos direitos fundamentais às relações privadas tendo em vista que eles foram postos, inicialmente, como forma de limitação ao poder do Estado, que seria, naquele momento, seu único destinatário.

De fato, nos países como os Estados Unidos, em que se adota a state action doctrine, ainda é visível a dicotomia entre direito privado e direito público. Naquele país, a possibilidade de aplicação de direitos fundamentais de primeira dimensão às relações privadas é limitada às hipóteses em que a violação decorrer de alguma ação tida como estatal, mantendo-se a doutrina liberal em que tais direitos não vinculam os particulares, em que pese as críticas e ponderações ${ }^{6}$.

$\mathrm{Na}$ Alemanha, o marco inicial sobre o a eficácia horizontal dos direitos fundamentais se deu no caso Lüth, jugado pela Corte constitucional Alemã em 1958. Tal caso tratava da tentativa de boicote, conclamada pelo Presidente do Clube de Imprensa de Hamburgo (Erich Lüth) a filme dirigido por um cineasta que, à época de Hitler, elaborou filme antissemita. Neste caso, o Tribunal de Hamburgo determinou que Lüth cessasse a conclamação ao boicote, mas tal decisão foi reformada pela Corte Constitucional entendeu que não poderia haver tal violação ao direito fundamental de liberdade de expressão.

Ainda que com a reforma da decisão, a ideia de eficácia horizontal dos direitos fundamentais se desenvolveu naquele país, em que "deduziu-se da dimensão objetiva dos direitos fundamentais um efeito de irradiação destes sobre todo o sistema normativo."7 Neste sentido cunhou-se incialmente a expressão drittwirkung der grundrechte (eficácia perante terceiros) em relação à aplicação dos direitos fundamentais nas relações privadas.

No entanto, tal termo sofreu diversas críticas, entre elas a de que equiparou o terceiro ao Estado, sem fazer as devidas distinções. Estas críticas fizeram surgir a expressão horizontalwirkung, que também foi objeto de ponderações por parte da doutrina por pressupor a igualdade dentre os particulares, o que, em grande parte das vezes, não se verifica. Cabe ressaltar que na doutrina alemã, Alexy $^{8}$ também reconhece que a influência dos direitos

\footnotetext{
${ }^{6}$ Em especial as do movimento Critical Legal Studies, conforme informado por Sarmento em SARMENTO, Daniel. Direitos Fundamentais e Relações Privadas. Rio de Janeiro: Lumen Iuris, 2004. p. 234-237.

${ }^{7}$ PEREIRA, Jane Reis Gonçalves. Apontamentos sobre a aplicação das normas de direito fundamental nas relações jurídicas entre particulares. In: BARROSO, Luís Roberto (Org.). A Nova Interpretação Constitucional: Ponderação, Direitos Fundamentais e Relações Privadas. 3. ed. Rio de Janeiro: Renovar, 2008. p. 153

${ }^{8}$ ALEXY, Robert. Teoría de los derechos fundamentales. 2. ed. Madrid: Centro de Estudios Politicos y Constitucionales, 2008. p.464
} 
fundamentais vai além da relação Estado - cidadão, atingindo a esfera de relações entre particulares.

Destaca-se a relevância conferida à ideia de supremacia constitucional, que pressupõe a necessidade de adaptação do direito ordinário às normas constitucionais. Além disso, a dimensão objetiva também pressupõe a ideia de eficácia entre particulares dos direitos fundamentais. Conforme bem elucida Pereira, "a admissão da eficácia dos direitos fundamentais em relações inter privatos pode ser entendida como a consequência mais importante do reconhecimento da sua dimensão objetiva." 9

No Brasil, a Constituição da República de 1988, através de suas garantias dos direitos fundamentais e da dignidade da pessoa, proporciona sua irradiação para diversos ramos do direito, incluindo o direito privado. Decerto que não apenas o Estado, mas pessoas privadas, são capazes de violar os direitos fundamentais tendo em vista, por exemplo, as relações de dominação econômica.

Hodiernamente, a dimensão objetiva dos direitos fundamentais é reconhecida ${ }^{10}$, mas carece de consenso em relação ao conteúdo e efeitos da aplicação dessa mesma categoria jurídica ao direito privado. A questão que se põe é saber quais são os efeitos jurídicos do reconhecimento da irradiação dos direitos fundamentais às relações entre particulares e de que modo são harmonizados os direitos e deveres entre as partes.

\subsection{Eficácia mediata e imediata}

Inicialmente cabe destacar que há uma convergência entre ambas as teorias, as quais preconizam que os direitos fundamentais derivam de uma ordem de valores que irradia efeitos em todo o direito, representando escolhas axiológicas da sociedade. Partindo dessa premissa, a teoria da eficácia mediata entende que não há a incidência direita nas relações privadas, mas apenas uma diretriz interpretativa que deve ser considerada quando da elaboração das leis ou de sua intepretação.

Deste modo, para a teoria da eficácia mediata, é necessária a atuação estatal, pois este é o destinatário imediato de tais normas. Para esta teoria, cabe ao legislador, através da edição de

\footnotetext{
${ }^{9}$ PEREIRA, Jane Reis Gonçalves. Apontamentos sobre a aplicação das normas de direito fundamental nas relações jurídicas entre particulares. In: BARROSO, Luís Roberto (Org.). A Nova Interpretação Constitucional: Ponderação, Direitos Fundamentais e Relações Privadas. 3. ed. Rio de Janeiro: Renovar, 2008. p. 154

${ }^{10}$ Tal reconhecimento é pacífico no panorama romano-germânico, em que pese a existência da tese que nega a aplicação dos direitos fundamentais às relações privadas, conforme elucida Sarmento em SARMENTO, Daniel. Direitos Fundamentais e Relações Privadas. Rio de Janeiro: Lumen Iuris, 2004. p. 197-198
} 
normas do direito privado, disciplinar a aplicação dos direitos fundamentais às pessoas privadas. Não há, para esta corrente, uma limitação direta da atuação do ente privado pela aplicação dos direitos fundamentais. Isso não significa que os direitos fundamentais estejam desprotegidos. Há proteção, não pelo direito constitucional, mas sim pelos mecanismos já existentes no direito privado, caso tenham sido objeto de específica opção legislativa.

A teoria da eficácia mediata preconiza que, em caso de conflito entre os princípios, caberia à lei estabelecer em que grau cada princípio deveria ceder em respeito aos princípios da segurança jurídica, separação de poderes e democracia. O papel do Judiciário seria apenas preencher as lacunas das cláusulas gerais criadas pelo legislador e declarar eventuais inconstitucionalidades em caso de incompatibilidades. Deste modo,

$$
\begin{aligned}
& \text { apenas em casos excepcionais, de lacuna do ordenamento privado, e de inexistência } \\
& \text { de cláusula geral ou de conceito indeterminado que possa ser preenchido em harmonia } \\
& \text { com os valores constitucionais, é que se permitiria ao juiz a aplicação direta dos } \\
& \text { direitos fundamentais nas relações privadas, independentemente da mediação do } \\
& \text { legislador. }{ }^{11}
\end{aligned}
$$

Assim, para a teoria da eficácia mediata há "portas de conexão", pelas quais entram os direitos fundamentais no direito privado, como sistematizado por Gunther Dürig, conforme elucida Pereira ${ }^{12}$. Não obstante, a norma de direito privado continuaria sendo uma norma de direito privado, que, em relação ao juiz "el efecto de irradiación deveria fundamentar el deber de tener em cuenta em su interpretación la influencia iusfundamental em las normas de derecho privado." 13

Sarmento $^{14}$ alerta para as diferenças entre o sistema constitucional alemão e brasileiro, como forma de demonstrar que a tese adotada no país germânico não tem cabimento aqui. A Carta alemã, diferentemente da brasileira, não elenca (com exceção de um artigo) direitos fundamentais dirigidos contra particulares. Ademais, não elenca direitos sociais e, no Brasil, a sociedade, como um todo, é muito mais injusta do que na Alemanha ou mesmo EUA.

\footnotetext{
${ }^{11}$ SARMENTO, Daniel. Direitos Fundamentais e Relações Privadas. Rio de Janeiro: Lumen Iuris, 2004. p. 241

12 PEREIRA, Jane Reis Gonçalves. Apontamentos sobre a aplicação das normas de direito fundamental nas relações jurídicas entre particulares. In: BARROSO, Luís Roberto (Org.). A Nova Interpretação Constitucional: Ponderação, Direitos Fundamentais e Relações Privadas. 3. ed. Rio de Janeiro: Renovar, 2008. p. 160

13 ALEXY, Robert. Teoría de los derechos fundamentales. 2. ed. Madrid: Centro de Estudios Politicos y Constitucionales, 2008. p. 469
} 
A teoria da eficácia imediata reconhece que, juntamente aos direitos fundamentais clássicos (em face do Estado), existem outros, que influem diretamente na esfera dos direitos privados subjetivos dos indivíduos. Tal não ocorre em decorrência de uma forma de interpretação ou de uma cláusula geral, mas sim como efeitos diretos e normativos, que "assumem a condição de direitos subjetivos em face de pessoas privadas que assumam posições de poder." 15

Esta posição é criticada pela teoria da eficácia mediata posto que o reconhecimento da eficácia direta importaria, em última análise, no total esvaziamento da autonomia privada. No entanto, como esclarece Sarmento ${ }^{16}$, a teoria da eficácia imediata não nega a necessidade de ponderação entre os direitos fundamentais e a autonomia privada e as especificidades de sua aplicação, não se traduzindo em uma doutrina radical.

A teoria da eficácia mediata foi adotada pela Corte Constitucional Alemã no caso Lüth e tem prevalecido na doutrina majoritária daquele país. No entanto, conforme informado por Pereira ${ }^{17}$, tal opção tem prevalecido por questões processuais. A referida autora esclarece que, caso fosse admitida a eficácia imediata, o sistema de controle concentrado associado à sistemática do recurso constitucional levaria ao reconhecimento da competência da Corte para examinar as violações em uma infinidade de ações. Isso levaria o tribunal constitucional a se transformar em uma instância superior de resolução de conflitos cíveis, esvaziando seu papel constitucional.

Sarmento ${ }^{18}$ sintetiza e rebate as demais críticas à teoria da eficácia imediata. Em relação à contradita de que tal teoria violaria a autonomia privada, o doutrinador afirma que esta, por não ser valor absoluto, pode ser ponderada e que a eficácia imediata não importa na necessária prevalência dos direitos fundamentais em seu detrimento. Além disso, ressalta que só há autonomia se houver liberdade material, ou seja, a possibilidade de autodeterminação do sujeito, que em muitos casos não se mostra presente.

\footnotetext{
15 PEREIRA, Jane Reis Gonçalves. Apontamentos sobre a aplicação das normas de direito fundamental nas relações jurídicas entre particulares. In: BARROSO, Luís Roberto (Org.). A Nova Interpretação Constitucional: Ponderação, Direitos Fundamentais e Relações Privadas. 3. ed. Rio de Janeiro: Renovar, 2008. p. 159

${ }^{16}$ SARMENTO, Daniel. Direitos Fundamentais e Relações Privadas. Rio de Janeiro: Lumen Iuris, 2004. p. 284

17 PEREIRA, Jane Reis Gonçalves. Apontamentos sobre a aplicação das normas de direito fundamental nas relações jurídicas entre particulares. In: BARROSO, Luís Roberto (Org.). A Nova Interpretação Constitucional: Ponderação, Direitos Fundamentais e Relações Privadas. 3. ed. Rio de Janeiro: Renovar, 2008. p. 166-168
} 
Nos Estados Unidos, como o texto constitucional aponta o Estado como destinatário dos direitos de liberdade, o entendimento é que os direitos individuais são oponíveis apenas ao Estado. Assim, a aplicação aos particulares se dá apenas no caso em que se identifique uma ação estatal, mesmo que indireta, conforme preceitua a doutrina do state action. Deste modo, a Suprema Corte reconheceu que a proteção (equal protection) deveria ser concedida contra condutas não só de agentes públicos estatais, mas também de particulares que atuam exercendo poderes estatais (state-given power), como o caso dos partidos políticos, por exemplo. Além disso, a Suprema Corte dos Estados Unidos entendeu que, embora as estipulações contratuais discriminatórias, por si só, não ensejam violação à igualdade, a intervenção estatal visando sua execução forçada (enforcement) enseja, sendo cabível a aplicação da proteção.

$\mathrm{Na}$ doutrina brasileira, Daniel Sarmento, com fundamento na moldura axiológica estabelecida pela $\mathrm{CRFB} / 88$, afirma que "no caso brasileiro, a eficácia dos direitos fundamentais nas relações privadas é direta e imediata, não dependendo da atuação do legislador ordinário, nem se exaurindo na interpretação das cláusulas gerais do Direito Privado.”19

No Supremo Tribunal Federal, há aplicação dos direitos fundamentais às relações privadas. Embora ainda não tenha sido apreciada pelo pleno do Supremo Tribunal Federal, "a discussão está firmemente estabelecida no Brasil, com franca prevalência da tese da eficácia imediata"20.

\subsection{Teoria dos deveres de proteção}

Parte da doutrina alemã defende que esta teoria é a mais adequada para solucionar as questões que envolvam a aplicação dos direitos fundamentais às relações privadas. Como elucida Sarmento "a teoria dos deveres de proteção baseia-se na ideia de que a conciliação entre a autonomia privada e os direitos fundamentais deve incumbir ao legislador e não ao Judiciário"24. No entanto, quando o legislador não protege adequadamente o direito fundamental ou mesmo a autonomia privada no caso concreto, o Judiciário pode atuar, mas através de controle de constitucionalidade.

\footnotetext{
${ }^{19}$ SARMENTO, Daniel. Direitos Fundamentais e Relações Privadas. Rio de Janeiro: Lumen Iuris, 2004. p. 279

${ }^{20}$ PEREIRA, Jane Reis Gonçalves. Apontamentos sobre a aplicação das normas de direito fundamental nas relações jurídicas entre particulares. In: BARROSO, Luís Roberto (Org.). A Nova Interpretação Constitucional: Ponderação, Direitos Fundamentais e Relações Privadas. 3. ed. Rio de Janeiro: Renovar, 2008. p. 181

${ }^{24}$ SARMENTO, Daniel. A Vinculação dos Particulares aos Direitos Fundamentais no Direito Comparado e no Brasil. In: BARROSO, Luís Roberto (Org.). A Nova Interpretação Constitucional: Ponderação, Direitos Fundamentais e Relações Privadas. 3. ed. Rio de Janeiro: Renovar, 2008. p. 239
} 
A teoria dos direitos de proteção impõe um dever de atuação do Estado no sentido de evitar lesões aos bens jurídicos fundamentais. Deste modo, "partindo-se dessa noção é possível extrair da dimensão objetiva um direito subjetivo, consubstanciado no poder de reclamar do Estado uma atuação consistente em resguardar os direitos fundamentais de ameaças, mesmo que perpetradas por particulares." 25 Há um dever do legislador em tutelar e desenvolver os direitos fundamentais, assim como há um dever dos magistrados em efetivá-los mediante sua atividade interpretativa do direito.

Deste modo, na prática, tal teoria se assemelha à teoria da eficácia mediata dos direitos fundamentais, razão pela qual sofre diversas críticas. Uma delas é de que nega uma proteção adequada aos direitos fundamentais, além do fato que a proteção fica à mercê do legislador e que o sistema de controle de constitucionalidade pode ser falho.

Sarmento $^{26}$ adverte que o dever de proteção dos direitos fundamentais por particulares se limita às relações em que estes são partes, ou seja, o particular não está vinculado a um dever de proteção quando o direito fundamental está sendo violado por terceiro. Este dever cabe ao Estado, através dos Poderes Legislativo, Executivo e Judiciário.

\section{Limitação à autonomia privada}

\subsection{Aplicação direta dos direitos fundamentais}

A autonomia privada pode ser entendida como "a capacidade do sujeito de direito de determinar seu próprio comportamento individual" 27 . Deste modo, os particulares possuem uma esfera de liberdade protegida juridicamente. Tal esfera se traduz tanto na autodeterminação de modo de vida como de questões negociais. Evidentemente, a influência dos direitos fundamentais na limitação da primeira é muito mais presente do que na segunda. Deste modo, destaca-se que embora a autonomia privada constitua um valor essencial nos Estados Democráticos, nem todas as suas manifestações possuirão a mesma proteção constitucional. Assim, as questões existenciais demandarão maior proteção dos que as econômicopatrimoniais.

\footnotetext{
${ }^{25}$ PEREIRA, Jane Reis Gonçalves. Apontamentos sobre a aplicação das normas de direito fundamental nas relações jurídicas entre particulares. In: BARROSO, Luís Roberto (Org.). A Nova Interpretação Constitucional: Ponderação, Direitos Fundamentais e Relações Privadas. 3. ed. Rio de Janeiro: Renovar, 2008. p. 154

${ }^{26}$ SARMENTO, Daniel. Direitos Fundamentais e Relações Privadas. Rio de Janeiro: Lumen Iuris, 2004. p. 300

${ }^{27}$ SARMENTO, Daniel. Direitos Fundamentais e Relações Privadas. Rio de Janeiro: Lumen Iuris, 2004. p. 174
} 
Como adverte Sarmento $^{28}$, a vinculação direta dos direitos fundamentais não importa na aplicação destes direitos às relações privadas da mesma forma que é feita nas relações de direito público. Isto porque os particulares também gozam de direitos fundamentais e de autonomia privada, que, do mesmo modo, são protegidos constitucionalmente. No entanto, isto não significa que a autonomia privada negocial esteja imune à incidência dos direitos fundamentais como forma de limitação.

A autonomia também é expressão da dignidade da pessoa humana. Alexy, ao analisar a crítica de que a aplicação direta dos direitos fundamentais eliminaria a autonomia privada, afirma que este é "un problema de ponderación." 29 Assim, quando em conflito com outros direitos fundamentais que também decorrem da proteção à dignidade, há que se fazer uma ponderação para verificar qual deles deve prevalecer.

Sarmento também entende que "a fixação de limites para a incidência dos direitos fundamentais nas relações entre particulares envolve um problema de ponderação com a autonomia privada"30. Entretanto, não basta a análise simplista entre colisão entre princípios de proteção à pessoa e de proteção economia para concluir pela prevalência absoluta do primeiro.

O ponto sensível nesta questão é saber o quanto poderá ser limitada a autonomia privada em matéria negocial. De um lado, tal limitação não pode ser ardil para que um dos contratantes se exima de obrigação validamente constituída. De outro, a autonomia privada não deve servir como meio de subjugar um particular em uma relação jurídica em que a liberdade é meramente formal.

Neste sentido, bem adverte Negreiros ${ }^{31}$ que "o fato de se reconhecer a primazia das situações existenciais sobre as situações de cariz econômico-patrimonial, como necessário desdobramento do valor da pessoa humana é insuficiente como critério de harmonização de princípios." Sarlet ${ }^{32}$, sem poder afirmar uma consolidação jurisprudencial sobre o tema, denota

\footnotetext{
${ }^{28}$ SARMENTO, Daniel. Direitos Fundamentais e Relações Privadas. Rio de Janeiro: Lumen Iuris, 2004. p. 301

29 ALEXY, Robert. Teoría de los derechos fundamentales. 2. ed. Madrid: Centro de Estudios Politicos y Constitucionales, 2008. p. 479

${ }^{30}$ SARMENTO, Daniel. Direitos Fundamentais e Relações Privadas. Rio de Janeiro: Lumen Iuris, 2004. p. 302

${ }^{31}$ NEGREIROS, Teresa. A Dicotomia Público-Privado frente ao Problema da Colisão de Princípios. In: TORRES, Ricardo Lobo (Org.). Teoria dos Direitos Fundamentais. 2. ed. Rio de Janeiro: Renovar, 2001. p. 346

${ }^{32}$ SARLET, Ingo Wolfgang. Notas sobre a Dignidade da Pessoa na Jurisprudência do Supremo Tribunal Federal. In: SARMENTO, Daniel; SARLET, Ingo Wolfgang. (Coord.). Direitos Fundamentais no Supremo Tribunal Federal: balanço e críticas. Rio de Janeiro: Lumen Iuris, 2011. p. 69
} 
que o Supremo Tribunal Federal tem utilizado a dignidade como critério de proporcionalidade quando da hipótese de conflito entre direitos fundamentais.

A liberdade individual deve ser respeitada não só pelo Estado, mas pelos demais detentores de poder que integram a sociedade civil. E, neste contexto, se não há condições mínimas de vida, não há como se falar em liberdade. Como é cediço, o Brasil é um país com níveis alarmantes de desigualdade social e, em que pese os esforços de mudança, ainda existem pessoas sem condições financeiras mínimas de manter sua própria subsistência, o que leva ao uso desmedido do crédito até mesmo como forma de pertencimento a uma sociedade de consumo.

Nestes casos, não há como afirmar que exista uma liberdade material posto que tais pessoas não possuem os meios necessários para sua autodeterminação. Sarmento, apontando o consenso doutrinário sobre a questão, sintetiza que "a liberdade é esvaziada quando não são asseguradas as condições materiais mínimas para que as pessoas possam desfrutá-las de forma consciente". ${ }^{33}$ Neste sentido, a autonomia privada pode acabar se tornando meio para imposição da vontade da parte detentora de poder na sociedade, como já advertiu Lacordaire em sua célebre frase: "entre o fraco e o forte é a liberdade que escraviza e a lei que liberta" 34 .

É indubitável que as instituições financeiras e grandes fornecedores de bens e serviços são detentoras de poder econômico dentro da sociedade. Em razão disto, o texto constitucional demonstra que a atividade econômica está sujeita à realização de finalidades sociais, tanto para a construção de uma sociedade livre, justa e solidária, conforme determina o art. $3^{\circ}$, I, quanto para assegurar a todos uma existência digna, conforme os ditames da justiça social, nos termos do caput do art. 170 da Carta Maior.

Evidentemente que a relação entre instituição financeira e o consumidor de crédito é desigual. No entanto, não se pode afirmar que em todo e qualquer caso a autonomia privada estaria em risco, devendo ser mitigada pela eficácia imediata dos direitos fundamentais. Uma das críticas formuladas à teoria da eficácia imediata, é que sua adoção importaria na aniquilação da autonomia privada, o que é refutado pela doutrina.

No entanto, a questão não é o esvaziamento da autonomia privada, mas a análise, no caso concreto, se ela deve prevalecer em face dos demais direitos fundamentais nas relações

\footnotetext{
${ }^{33}$ SARMENTO, Daniel. Direitos Fundamentais e Relações Privadas. Rio de Janeiro: Lumen Iuris, 2004. p. 188

${ }^{34}$ Lacordaire apud GOMES, Orlando. Contratos. Rio de Janeiro: Forense, 1991 p. 35
} 
privadas, principalmente naquelas em que não há igualdade fática entre as partes posto que a autonomia pode não ser plena nas relações desiguais.

Ademais, os direitos fundamentais não vão incidir de forma absoluta e ilimitada às relações privadas. Cabe ao intérprete modular a extensão da incidência, considerando também a autonomia privada. A grande problemática nesta ponderação é em relação a adoção de métodos adequados, tendo em vista que "não é possível uma aplicação incondicionada destes ou da existência de setores completamente imunes à sua incidência"35

Ademais, Sarmento adverte que nos casos em que as pessoas manifestam o consentimento, como é nas questões contratuais, a análise da autonomia privada deve considerar "até que ponto é legítimo que os direitos fundamentais representem uma proteção da pessoa contra si mesma." 36 Nesta questão, o autor estabelece dois critérios de avaliação no que tange a tais limites: a vontade deve ser realmente livre e a renúncia ao exercício de direito fundamental não pode importar em lesão ao princípio da dignidade da pessoa humana ou violação ao núcleo essencial dos direitos fundamentais.

Além disso, critica-se que, numa relação entre particulares, a limitação da autonomia privada pelo poder público representaria uma expressão de paternalismo, indevida numa sociedade democrática. No entanto, Sarmento ${ }^{37}$ rebate tal crítica, rememorando que no Estado Liberal, a abstenção do Estado em intervir em determinadas questões, como a econômica, acabou favorecendo os mais poderosos. Deste modo, a intervenção do poder público, quando há a desigualdade entre as partes, não pode ser tolhida sob o argumento que tal intervenção representa a violação da autonomia das partes.

Canotilho, conforme elucida Sarmento, ressalta a importância da desigualdade da relação jurídica privada na intensidade da aplicação da eficácia horizontal dos direitos fundamentais e aponta alguns critérios que podem servir de solução no caso de conflitos:

(...) o Judiciário, no julgamento de um litígio privado deve, em primeiro lugar, aplicar as normas do Direito Privado em conformidade com os direitos fundamentais, pela via de interpretação conforme à Constituição. Se isso não for possível, ele deve recusar-se a aplicar ao caso a norma em questão, no exercício do controle incidental de constitucionalidade. E, em caso de ausência de norma ordinária apropriada, ele deve concretizar os direitos fundamentais, valendo-se não apenas das cláusulas gerais

\footnotetext{
35 PEREIRA, Jane Reis Gonçalves. Apontamentos sobre a aplicação das normas de direito fundamental nas relações jurídicas entre particulares. In: BARROSO, Luís Roberto (Org.). A Nova Interpretação Constitucional: Ponderação, Direitos Fundamentais e Relações Privadas. 3. ed. Rio de Janeiro: Renovar, 2008. p. 187

${ }^{36}$ SARMENTO, Daniel. Direitos Fundamentais e Relações Privadas. Rio de Janeiro: Lumen Iuris, 2004. p. 311

${ }^{37}$ SARMENTO, Daniel. Direitos Fundamentais e Relações Privadas. Rio de Janeiro: Lumen Iuris, 2004. p. 192 $-196$
} 
e conceitos indeterminados do próprio Direito Privado, mas também das próprias normas constitucionais consagradoras de tais direitos, cuja aplicação direta pelo Judiciário ele defende." 38

Assim, é possível a limitação da autonomia privada pela aplicação direta dos direitos fundamentais às relações privadas de forma a tornar a relação mais justa, desde que observados alguns critérios. Entre tais critérios destaca-se a desigualdade fática entre as partes pois "as pessoas privadas que se encontram em posição de supremacia devem ter suas ações limitadas pelos direitos fundamentais. Quanto mais intenso o poder da organização privada maior peso terá o direito fundamental que porventura venha a ser violado por suas ações."39

Por fim, cabe registrar a crítica feita por Silva ao critério de desigualdade fática utilizado por Sarmento para a limitação da autonomia privada:

\begin{abstract}
quero salientar que o recurso a desigualdades (fática e material), ainda que possa ser usado como elemento da argumentação jurídica nesse âmbito, deve ser encarado com extrema reserva. Parece-me que o decisivo é a sinceridade no exercício da autonomia privada, que não necessariamente terá alguma relação com desigualdades externas a ela. 40
\end{abstract}

\title{
3.2 Proporcionalidade e deveres de solidariedade
}

A aplicação direta dos direitos fundamentais não é a única forma encontrada pela doutrina para a limitação da autonomia privada. Dentre elas, destacam-se a aplicação do princípio da proporcionalidade e a existência de deveres de solidariedade, as quais passam a ser expostas de forma abreviada.

A aplicação do princípio da solidariedade é salientada por Steinmetz, para quem a autonomia privada e os direitos fundamentais têm estruturas de princípios, com o que concorda Silva ${ }^{41}$. Para tanto, é necessária a análise da necessidade, adequação e proporcionalidade em sentido estrito como forma de verificar se haverá ou não limitação da autonomia privada quando em colisão com algum direito fundamental. Partindo do conceito de precedência prima facie de Alexy ${ }^{42}$, Steinmetz desenvolve seu próprio modelo, em que há quatro precedências prima facie:

\footnotetext{
${ }^{38}$ SARMENTO, Daniel. Direitos Fundamentais e Relações Privadas. Rio de Janeiro: Lumen Iuris, 2004. p. 251

39 PEREIRA, Jane Reis Gonçalves. Apontamentos sobre a aplicação das normas de direito fundamental nas relações jurídicas entre particulares. In: BARROSO, Luís Roberto (Org.). A Nova Interpretação Constitucional: Ponderação, Direitos Fundamentais e Relações Privadas. 3. ed. Rio de Janeiro: Renovar, 2008. p. 189

${ }^{40}$ SILVA, Virgílio Afonso da. Direitos fundamentais e relações entre particulares. Revista Direito GV. v. 1 n. 1 p. 173 - 180. maio 2005. p. 176-177

${ }^{41}$ SILVA, Virgílio Afonso da. Direitos fundamentais e relações entre particulares. Revista Direito GV. v. 1 n. 1 p. 173 - 180. maio 2005. p. 176-177

${ }^{42}$ Steinmetz elucida o referido conceito: "precedências prima facie não contêm determinações definitivas em favor de um princípio [...], contudo estabelecem um ônus de argumentação para a precedência do outro princípio [...] no caso concreto. Assim, uma precedência prima facie constitui uma carga de argumentação a favor de um princípio
} 
1. Em uma relação contratual de particulares em situação (ou sob condições) de igualdade fática, há uma precedência prima facie do direito fundamental individual de conteúdo pessoal ante o princípio da autonomia privada.

2. Em uma relação contratual de particulares em situação (ou sob condições) de desigualdade fática, há uma precedência prima facie do direito fundamental individual de conteúdo pessoal ante o princípio da autonomia privada.

3. Em uma relação contratual de particulares em situação (ou sob condições) de igualdade fática, há uma precedência prima facie do princípio da autonomia privada ante o direito fundamental individual de conteúdo patrimonial.

4. Em uma relação contratual de particulares em situação (ou sob condições) de desigualdade fática, há uma precedência prima facie do direito fundamental individual de conteúdo patrimonial ante o princípio da autonomia privada ${ }^{43}$

Deste modo, observa-se uma aproximação com o critério de Sarmento de aplicação direta quando houver desigualdade fática, conforme já exposto neste trabalho. Silva critica o modelo desenvolvido por Steinmetz, tanto pela importância dada ao conceito de desigualdade, que para ele deveria ser substituída pelo conceito de sinceridade na autonomia privada, quanto pela utilização em si do princípio da proporcionalidade.

Nesta crítica, o autor expõe que o critério da necessidade não pode ser utilizado nos casos em que as partes sejam particulares (e não o Estado) pois "exigir que os particulares adotem (...) apenas as medidas estritamente necessárias (...) nada mais é do que retirar-lhes a autonomia de livremente dispor sobre os termos de seus contratos"44. Isto implicaria no desaparecimento da autonomia e não em uma solução do problema de sua colisão com os direitos fundamentais.

Outra forma de limitação à autonomia privada se dá pela aplicação dos deveres de solidariedade. A solidariedade é objetivo fundamental do Estado Brasileiro, conforme art. $3^{\circ}$, I da Constituição, e ratifica a incidência de direitos fundamentais. A Constituição não apresenta apenas normas que conferem direitos, mas apresenta diversos deveres dos sujeitos como membros do Estado. "Tem-se, assim, que os deveres fundamentais são correlatos aos direitos fundamentais (ou direitos da liberdade), pois se limitam por estes e se prestam ao mesmo tempo

\footnotetext{
e, por conseqüência, uma carga de argumentação contra o outro princípio" conforme STEINMETZ, Wilson. A Vinculação Dos Particulares A Direitos Fundamentais. São Paulo: Malheiros, 2004 p. 215 apud SILVA, Virgílio Afonso da. Direitos fundamentais e relações entre particulares. Revista Direito GV. v. 1 n. 1 p. 173 - 180. maio 2005. p. 178

${ }^{43}$ SILVA, Virgílio Afonso da. Direitos fundamentais e relações entre particulares. Revista Direito GV. v. 1 n. 1 p. 173 - 180. maio 2005. p. 178

${ }^{44}$ SILVA, Virgílio Afonso da. Direitos fundamentais e relações entre particulares. Revista Direito GV. v. 1 n. 1 p. 173 - 180. maio 2005. p. 179
} 
como garantia para o exercício da liberdade"45. Duque e Pedra conceituam os deveres fundamentais como:

deveres jurídicos da pessoa, tanto física quanto jurídica, que, por determinarem a posição fundamental do indivíduo, apresentam um significado para determinado grupo ou sociedade e, assim, podem ser exigidos numa perspectiva pública, privada, política, econômica e social. $^{46}$

Assim, há uma relação de reciprocidade entre direitos e deveres fundamentais, determinados pelo dever de prestar solidariedade. Com isso, o particular possui o dever fundamental implícito de respeito ao outro particular em matéria contratual, o que configura os deveres anexos.

A aplicação dos deveres de solidariedade pode ser forma de limitação à autonomia privada. No entanto, esta “só poderá ser relativizada (...) quando pautada em critérios racionalmente justificáveis e utilizando-se do diálogo das fontes ${ }^{\text {} 47}$, que é forma de superar antinomias e buscar soluções coerentes através da interpretação sistemática das normas. Duque e Pedra alertam ainda que a limitação à autonomia privada não pode se dar através de "dirigismo contratual sem critérios e de forma absoluta, para impor aos indivíduos e empresas alguns deveres tipicamente estatais" mas sim "para exigir o cumprimento do dever anexo de solidariedade, pautado em critérios objetivos de violação a deveres de condutas". 48

\section{Aplicação ao consumidor superendividado}

A autonomia privada pode ser ponderada pela aplicação direta dos direitos fundamentais, para que se possa assegurar a dignidade da pessoa humana. Há, acerca do conceito de dignidade da pessoa, falta de consenso doutrinário, conforme adverte Sarlet ${ }^{49}$, tendo em vista a dificuldade de sua enunciação, do uso de conceitos de contornos vagos e imprecisos,

\footnotetext{
45 DUQUE, Bruna Lyra; PEDRA, Adriano Sant'Ana. Os deveres fundamentais e a solidariedade nas relações privadas. Revista de Direitos Fundamentais e Democracia. Curitiba, v. 14, n. 14, p. 147-161, jul./dez. 2013 . p. 148

${ }^{46}$ DUQUE, Bruna Lyra; PEDRA, Adriano Sant ${ }^{A} A n a$. Os deveres fundamentais e a solidariedade nas relações privadas. Revista de Direitos Fundamentais e Democracia. Curitiba, v. 14, n. 14, p. 147-161, jul./dez. 2013. p. 151

${ }^{47}$ DUQUE, Bruna Lyra; PEDRA, Adriano Sant'Ana. Os deveres fundamentais e a solidariedade nas relações privadas. Revista de Direitos Fundamentais e Democracia. Curitiba, v. 14, n. 14, p. 147-161, jul./dez. 2013. p. 159

${ }^{48}$ DUQUE, Bruna Lyra; PEDRA, Adriano Sant'Ana. Os deveres fundamentais e a solidariedade nas relações privadas. Revista de Direitos Fundamentais e Democracia. Curitiba, v. 14, n. 14, p. 147-161, jul./dez. 2013. p. 155

49 SARLET, Ingo Wolfgang. Notas sobre a Dignidade da Pessoa na Jurisprudência do Supremo Tribunal Federal. In: SARMENTO, Daniel; SARLET, Ingo Wolfgang. (Coord.). Direitos Fundamentais no Supremo Tribunal Federal: balanço e críticas. Rio de Janeiro: Lumen Iuris, 2011. p. 39
} 
caracterizados por sua ambiguidade e porosidade, cuja natureza é necessariamente polissêmica.

No entanto, o próprio doutrinador fornece sua definição de dignidade:

qualidade intrínseca e distintiva reconhecida em cada ser humano que o faz merecedor do mesmo respeito e consideração por parte do Estado e da comunidade, implicando, neste sentido, um complexo de direitos e deveres fundamentais que assegurem a pessoa tanto contra todo e qualquer ato de cunho degradante e desumano, como venham a lhe garantir as condições existenciais mínimas para uma vida saudável, além de propiciar e promover sua participação ativa e co-responsável nos destinos da própria existência e da vida em comunhão com os demais seres humanos, mediante o devido respeito aos demais seres que integram a teia da vida. ${ }^{50}$

Sarlet cita os ensinamentos de Martin Koppernock, endossado por diversos outros doutrinadores, para afirmar que:

mesmo presente em sua plenitude, a autonomia da vontade (dignidade como capacidade de autodeterminação), esta poderia ser relativizada em face da dignidade na sua dimensão assistencial (protética), já que, em determinadas circunstâncias, nem mesmo o livre consentimento autoriza determinados procedimentos, tal como ocorre v. g., com a extração de todos os dentes de um paciente sem qualquer tipo de indicação médica, especialmente quando o consentimento estiver fundado na ignorância técnica. ${ }^{51}$

Isto por que a dignidade cumpre dupla função: limite - para a intervenção do Estado e de terceiros (inclusive para efeito da proteção da pessoa contra si mesma) - e tarefa - no sentido de gerar um dever jurídico de atuação em prol da proteção da dignidade. Para Sarmento ${ }^{52}$, a proteção conferida à dignidade pela ordem constitucional pode ser preventiva ou repressiva e englobar prestações negativas e positivas dependendo do caso concreto. Deste modo, é possível afirmar que a desigualdade material justifica a ampliação da proteção dos direitos fundamentais na esfera privada. Em relação ao tema, Vieira de Andrade salienta que:

põe-se em relevo a necessidade de protecção dos particulares não apenas perante o Estado, mas também, através do Estado, perante outros particulares, pelo menos, perante indivíduos ou entidades privadas que sobre eles exercem ou estão em condições de exercer verdadeiros poderes, jurídicos ou de facto. ${ }^{53}$

Sarmento adverte ainda que certas instituições privadas possuem poderes normativos, institucionalizados ou tolerados pela ordem jurídica, o que denota a necessidade de proteção em face da desigualdade na relação jurídica. Tal doutrinador conclui que

\footnotetext{
${ }^{50}$ SARLET, Ingo Wolfgang. Notas sobre a Dignidade da Pessoa na Jurisprudência do Supremo Tribunal Federal. In: SARMENTO, Daniel; SARLET, Ingo Wolfgang. (Coord.). Direitos Fundamentais no Supremo Tribunal Federal: balanço e críticas. Rio de Janeiro: Lumen Iuris, 2011. p. 51

${ }^{51}$ SARLET, Ingo Wolfgang. Notas sobre a Dignidade da Pessoa na Jurisprudência do Supremo Tribunal Federal. In: SARMENTO, Daniel; SARLET, Ingo Wolfgang. (Coord.). Direitos Fundamentais no Supremo Tribunal Federal: balanço e críticas. Rio de Janeiro: Lumen Iuris, 2011. P. 46, nota de rodapé no 27.

${ }^{52}$ SARMENTO, Daniel. Direitos Fundamentais e Relações Privadas. Rio de Janeiro: Lumen Iuris, 2004. P. 301

53 ANDRADE, Vieira de. Os Direitos Fundamentais do Século XXI [on line]. Disponível em < http://georgemlima.xpg.uol.com.br/andrade.pdf> , acesso em 07/07/15. P. 33
} 
em certos domínios normativos, como o Direito do Trabalho e o Direito do Consumidor, que têm como premissa a desigualdade fática entre as partes, a vinculação aos direitos fundamentais deve mostrar-se especialmente enérgica, enquanto a argumentação ligada à autonomia da vontade dos contratantes assume peso inferior. ${ }^{54}$

De acordo com Sarmento "quanto maior a desigualdade, mais intensa será a proteção do direito fundamental em jogo e menor a tutela da autonomia privada" ${ }^{25}$. Ao contrário, quanto mais paritária a relação, maior é a proteção à autonomia privada.

Não há dúvidas acerca da posição dominante que exercem os bancos e instituições financeiras na sociedade. Assim, haverá a vinculação direta destas instituições aos direitos fundamentais e a desigualdade material torna-se especialmente relevante no momento em que se tiver de ponderar o direito em questão com a autonomia privada. Vieira de Andrade também se posiciona de forma favorável à aplicação direta nos casos em que há relação de poder entre as partes:

\begin{abstract}
Quanto a nós, para além dos casos já referenciados em que a Constituição expressamente concebe os direitos perante privados, só deverá aceitar-se esta transposição directa dos direitos fundamentais, enquanto direitos subjectivos, para as relações entre particulares quando se trate de situações em que pessoas colectivas (ou, excepcionalmente, indivíduos) disponham de poder especial de carácter privado sobre (outros) indivíduos. Em tais casos, estamos perante relações de poder - e não relações entre iguais - e justifica-se a proteção da liberdade dos homens comuns que estejam em posição de vulnerabilidade. ${ }^{56}$
\end{abstract}

Diante disso, a desigualdade na relação jurídica é critério relevante para ponderação da autonomia privada em face da proteção à dignidade. A caracterização da igualdade ou desigualdade é obtida através da comparação de situações e pessoas, pois é uma "visão macro, do homem e da sociedade" ${ }^{\Perp 57}$. O Código de Defesa do Consumidor, em seu art. $4^{\mathrm{o}}$, I, presume a vulnerabilidade do consumidor. A vulnerabilidade é derivada da igualdade, mas diferencia-se dela por ser "um estado da pessoa, um estado inerente de risco" 58 .

Muitas instituições fornecem crédito de forma irrestrita inadequada, lesando o consumidor, que, muitas vezes, imbuído na ilusão do “dinheiro rápido e fácil” perde o controle

\footnotetext{
${ }^{54}$ SARMENTO, Daniel. Direitos Fundamentais e Relações Privadas. Rio de Janeiro: Lumen Iuris, 2004. P. 305

${ }^{55}$ SARMENTO, Daniel. Direitos Fundamentais e Relações Privadas. Rio de Janeiro: Lumen Iuris, 2004. p. 303

${ }^{56}$ ANDRADE, Vieira de. Os Direitos Fundamentais do Século XXI [on line]. Disponível na internet via WWW. URL:<http://georgemlima.xpg.uol.com.br/andrade.pdf>. Última atualização em 07 de julho de 2015. p. 41

${ }^{57}$ MARQUES, Cláudia Lima; BENJAMIN; Antônio Herman V.; MIRAGEM; Bruno. Comentários ao Código de Defesa do Consumidor: arts. $1^{\circ}$ a 74: Aspectos Materiais. São Paulo: Editora Revista dos Tribunais, 2003. p. 120

${ }^{58}$ MARQUES, Cláudia Lima; BENJAMIN; Antônio Herman V.; MIRAGEM; Bruno. Comentários ao Código de Defesa do Consumidor: arts. $1^{\circ}$ a 74: Aspectos Materiais. São Paulo: Editora Revista dos Tribunais, 2003. p. 120
} 
de sua própria situação financeira, e, quando percebe, já está superendividado. Evidencia-se, portanto, a vulnerabilidade dos consumidores de crédito, que decorre da desigualdade fática que autoriza a ponderação entre a autonomia de vontade e o respeito aos direitos fundamentais de modo a assegurar a dignidade dos consumidores de crédito.

A limitação à autonomia privada é um dos meios necessários à renegociação das dívidas e a readequação dos contratos, mesmo que deles não constem, a priori, cláusulas abusivas. Uma das principais sugestões para tanto, que vem sendo tratada no PL 283 de 2012, inspirada na legislação francesa, é a renegociação. Tal procedimento ocorreria como num plano de recuperação do superendividado, o que importa o chamamento dos credores para que possam modificar os contratos vigentes e validamente constituídos.

\begin{abstract}
O acordo com os credores traduz-se na aprovação de um plano destinado a conseguir, no final da sua vigência, o saneamento da situação patrimonial ou do superendividamento do devedor, mediante a adoção das medidas de reestruturação aceitas pelo devedor e seus credores. O plano poderá conter medidas de temporização ou reescalonamento do pagamento das dívidas, de remissão das mesmas, de redução ou de supressão da taxa de juros, de consolidação, de criação ou de substituição das garantias, entre outras medidas indispensáveis para adequar o passivo às possibilidades de cumprimento efetivo do devedor em questão. ${ }^{59}$
\end{abstract}

Com isso, fica evidenciada a necessidade de flexibilização da autonomia privada em respeito aos direitos fundamentais do consumidor. Por fim, resta salientar que "a proteção do consumidor superendividado recebe o amparo constitucional na medida em que a prevenção e o tratamento deste fenômeno serão formas de assegurar e/ou resgatar a dignidade dos indivíduos". ${ }^{6}$

Conclusão

O superendividamento é uma realidade para diversas famílias brasileiras, que não possuem condições de pagar as dívidas assumidas. Assim, o superendividamento coloca o consumidor em situação de vulnerabilidade. A impossibilidade de pagamento das dívidas assumidas dentro da esfera da autonomia de vontade acaba por violar a dignidade do consumidor de crédito, que não consegue arcar com sua própria subsistência.

Embora tramite o PL 283 de 2012, ainda não há no ordenamento jurídico brasileiro uma lei específica que regule a prevenção e tratamento do superendividado. Deste modo, diante da

\footnotetext{
59 MARQUES, Claudia Lima; LIMA, Clarissa Costa; BERTONCELLO, Káren. Prevenção e tratamento do superendividamento. Brasília: DPDC/SDE, 2010. P. 34-35

${ }^{60}$ MARQUES, Claudia Lima; LIMA, Clarissa Costa; BERTONCELLO, Káren. Prevenção e tratamento do superendividamento. Brasília: DPDC/SDE, 2010. p. 46
} 
sua vulnerabilidade, há que ser protegida a sua dignidade através da aplicação horizontal dos direitos fundamentais garantidos na CRFB 88.

Como ressaltado neste trabalho, a doutrina brasileira admite a aplicação direta dos direitos fundamentais às relações privadas. Tal aplicação direta é justificada pela posição de desigualdade entre as partes, como o é na relação banco-consumidor. No entanto, ressaltou-se que a aplicação direta dos direitos fundamentais, quando em conflito com outros princípios, como no caso da autonomia privada, exige a ponderação.

Verificada a desigualdade fática e a violação dos direitos fundamentais, são ponderados os princípios como forma de equilibrar a relação jurídica e torná-la mais justa. Em se concluindo pela limitação da autonomia privada, os contratos validamente constituídos podem ser revisados e medidas podem ser tomadas para o resguardo da dignidade da pessoa do consumidor superendividado e de seus familiares.

Referências bibliográficas

ALEXY, Robert. Teoría de los derechos fundamentales. 2. ed. Madrid: Centro de Estudios Politicos y Constitucionales, 2008.

ANDRADE, Vieira de. Os Direitos Fundamentais do Século XXI [on line]. Disponível na internet via WWW. URL:<http://georgemlima.xpg.uol.com.br/andrade.pdf >. Última atualização em 07 de julho de 2015.

CNC - Confederação Nacional do Comércio. Pesquisa Nacional de Endividamento e Inadimplência do Consumidor (Peic). [on line]. Disponível na internet via WWW. URL:<http://www.cnc.org.br/central-do-conhecimento/pesquisas/economia/pesquisanacional-de-endividamento-e-inadimplencia-do-c-7>. Última atualização em 07 de julho de 2015 .

DUQUE, Bruna Lyra; PEDRA, Adriano Sant'Ana. Os deveres fundamentais e a solidariedade nas relações privadas. Revista de Direitos Fundamentais e Democracia. Curitiba, v. 14, n. 14, p. 147-161, jul./dez. 2013

GOMES, Orlando. Contratos. Rio de Janeiro: Forense, 1991.

MARQUES, Cláudia Lima. Contratos no Código de Defesa do Consumidor: o novo regime das relações contratuais. 6. ed. São Paulo: Editora Revista dos Tribunais, 2011. 
MARQUES, Cláudia Lima; BENJAMIN; Antônio Herman V.; MIRAGEM; Bruno. Comentários ao Código de Defesa do Consumidor: arts. $1^{\text {o }}$ a 74: Aspectos Materiais. São Paulo: Editora Revista dos Tribunais, 2003.

MARQUES, Cláudia Lima; CAVALLAZZI, Rosângela Lunardelli. Direitos do Consumidor Endividado: Superendividamento e Crédito. São Paulo: Editora Revista dos Tribunais, 2006.

MARQUES, Claudia Lima; LIMA, Clarissa Costa; BERTONCELLO, Káren. Prevenção e tratamento do superendividamento. Brasília: DPDC/SDE, 2010.

NEGREIROS, Teresa. A Dicotomia Público-Privado frente ao Problema da Colisão de Princípios. In: TORRES, Ricardo Lobo (Org.). Teoria dos Direitos Fundamentais. 2. ed. Rio de Janeiro: Renovar, 2001.

PEREIRA, Jane Reis Gonçalves. Apontamentos sobre a aplicação das normas de direito fundamental nas relações jurídicas entre particulares. In: BARROSO, Luís Roberto (Org.). A Nova Interpretação Constitucional: Ponderação, Direitos Fundamentais e Relações Privadas. 3. ed. Rio de Janeiro: Renovar, 2008.

SARLET, Ingo Wolfgang. Notas sobre a Dignidade da Pessoa na Jurisprudência do Supremo Tribunal Federal. In: SARMENTO, Daniel; SARLET, Ingo Wolfgang. (Coord.). Direitos Fundamentais no Supremo Tribunal Federal: balanço e críticas. Rio de Janeiro: Lumen Iuris, 2011.

SARMENTO, Daniel. A Vinculação dos Particulares aos Direitos Fundamentais no Direito Comparado e no Brasil. In: BARROSO, Luís Roberto (Org.). A Nova Interpretação Constitucional: Ponderação, Direitos Fundamentais e Relações Privadas. 3. ed. Rio de Janeiro: Renovar, 2008.

SARMENTO, Daniel. Direitos Fundamentais e Relações Privadas. Rio de Janeiro: Lumen Iuris, 2004.

SILVA, Virgílio Afonso da. Direitos fundamentais e relações entre particulares. Revista Direito GV v. 1 n. 1 p. 173 - 180. maio 2005. 